\title{
PEMANTAUAN KEBIJAKAN PENATAAN PEDAGANG KAKI LIMA DI KECAMATAN GARUT KOTA OLEH TIM PENATAAN DAN PEMBERDAYAAN PEDAGANG KAKI LIMA KABUPATEN GARUT
}

\section{THE MONITORING ACTIVITIES STRUCTURING STREET VENDORS POLICY IN GARUT KOTA SUBDISTRICT BY TEAM ARRANGEMENT AND EMPOWERMENT OF STREET VENDORS GARUT}

\author{
Kurnia Muhamad Ramdhan; Asep Sumaryana; Slamet Usman Ismanto \\ kurniamr@yahoo.com; asep.sumaryana@unpad.ac.id; slamet.ismanto@unpad.ac.id \\ Program Studi Administrasi Publik \\ Fakultas Ilmu Sosial dan Ilmu Politik \\ Universitas Padjadjaran \\ Bandung, Indonesia
}

\begin{abstract}
ABSTRAK
Skripsi ini berupaya menyajikan hasil penelitian yang merefleksikan kegiatan Pemantauan Kebijakan Penataan Pedagang Kaki Lima di Kecamatan Garut Kota oleh Tim Penataan dan Pemberdayaan Pedagang Kaki Lima Kabupaten Garut. Latar belakang dari penelitian ini ialah tercetusnya kebijakan Penataan Pedagang Kaki Lima yang diprakarsai pada era kepemimpinan Rudy Gunawan selaku Bupati Garut Periode 2014 - 2019, sebagai upaya dalam menata kembali pusat perkotaan dan menertibkan para Pedagang Kaki Lima yang berjualan di sekitar pusat kota, hingga dalam praktiknya ditemukan suatu kendala dari pelaksanaan kebijakan tersebut yang disebabkan karena tidak efektifnya kegiatan pemantauan (monitoring) kebijakan. Teori yang digunakan dalam penelitian ini berasal dari William N. Dunn (1999), beliau mengemukakan bahwa Pemantauan setidaknya memainkan empat fungsi yaitu Eksplanasi, Akuntansi, Pemeriksaan, dan Kepatuhan. Penelitian ini dilakukan dengan menggunakan metode deskriptif dan pendekatan kualitatif. Data diperoleh dengan menggunakan studi kepustakaan dan studi lapangan berupa observasi nonpartisipan, wawancara mendalam, dan dokumentasi. Teknik triangulasi sumber dijadikan sebagai pemeriksaan keabsahan data dalam penelitian ini, kemudian data-data tersebut direduksi, disajikan, dan ditarik simpulan. Berdasarkan penelitian Penulis, nyatanya kegiatan pemantauan kebijakan tidak dapat dipandang sebelah mata, dikarenakan pemantauan kebijakan memiliki peran yang vital dalam menilai dan mengawal sejauh mana kebijakan yang sedang dilaksanakan dapat berjalan sesuai dengan koridor tujuan dan sasaran kebijakan tersebut, sehingga Pemantauan Kebijakan tidak dapat hanya dimaknai secara harfiah saja, perlu dilakukan elaborasi yang mendalam, seperti pada aspek Kepatuhan, Pemeriksaan, Akuntansi, dan/ atau Eksplanasi, karena hasil dari pemantauan kebijakan dapat dijadikan acuan untuk melakukan upaya koreksi/ modifikasi kebijakan.
\end{abstract}

Kata Kunci: Pemantauan Kebijakan, Penataan Pedagang Kaki Lima, Eksplanasi, Akuntansi, Pemeriksaan, Kepatuhan

\section{ABSTRACT}

This paper presents the results of research that seeks to reflect the monitoring activities Structuring Street Vendors Policy in Garut Kota subdistrict by Team Arrangement and Empowerment of Street Vendors Garut. The background of this study is that the conclusions of the policy Structuring Street Vendor initiated the era of the leadership of Rudy Gunawan as Garut Regent Period of 2014 - 2019, as an effort to restructure the urban centers and curb the street vendors who sell at around the center of town, up in practice 
found a constraint on the implementation of the policy caused by lack of effective monitoring policy.

The theory used in this study came from William N. Dunn (1999), he argued that the monitoring of at least play four functions, namely Explanation, Accounting, Auditing, and Compliance. This research is conducted by using descriptive and qualitative approach. Data obtained using literature study and field studies in the form of non-participant observation, in-depth interviews, and documentation. Triangulation techniques serve as a source of data validity checking in the study, then the data is reduced, presented, and the conclusions drawn. Based on the study of author, in fact monitoring policy can not be underestimated, because the monitoring policy has a vital role in assessing and guarding the extent to which the policy is being implemented to run in accordance with the corridor aims and objectives of the policy. So, the monitoring policy can not be simply interpreted a literal, depth elaboration is necessary, as in the aspect of Compliance, Auditing, Accounting, and/ or Explanation, because the results of the monitoring policy could be use as a reference to make efforts correction/modification of the policy.

Keywords: Policy Monitoring, Arrangement of Street Vendors, Explanation, Accounting, Auditing, Compliance

\section{PENDAHULUAN}

Garut Kota merupakan kecamatan yang terletak di Kabupaten Garut, Jawa Barat, dengan jumlah penduduk sebanyak 130.321 jiwa berdasarkan hasil sensus Badan Pusat Statistik Kabupaten Garut pada tahun 2015. Garut Kota sebagaimana pusat kota lainnya merupakan sentra dari beragam aktivitas kemasyarakatan, baik sebagai tempat bermukim, pemerintahan, perekonomian, perpolitikan, keagamaan, maupun kebudayaan. Beragam cara yang dilakukan masyarakat Garut Kota untuk bertahan hidup di tengah gempuran persaingan dan perkembangan zaman, menyempitnya lapangan pekerjaan, serta bertransformasinya sumber daya terampil menjadi mesin. Keanekaragaman yang ada menjadi potret heterogen perkotaan, termasuk dalam hal mencari nafkah yang di antaranya tercermin melalui fenomena Pedagang Kaki Lima (PKL) di Garut Kota sebagai salah satu sumber mata pencaharian masyarakat Kabupaten Garut.

Keberadaan PKL di Garut Kota bukanlah tanpa sebab, maraknya PKL yang menjajakan dagangannya seiring sejalan dengan perkembangan populasi manusia perkotaan yang kian meningkat tanpa diimbangi dengan ketersediaan lapangan pekerjaan maupun sumber mata pencaharian lainnya. Keberadannya tak lepas dari sejarah panjang perjalanan Kabupaten Garut semenjak masa kolonial hingga sekarang. Seiring berjalannya waktu, PKL Garut Kota berkembang pesat hingga menimbulkan kepadatan di zona merah (delapan titik), yaitu: 1) Jalan Jend. A. Yani; 2) Jalan Mandalagiri; 3) Jalan Pasar Baru; 4) Jalan Ciwalen; 5) Jalan Siliwangi; 6) Jalan Kiansantang; 7) Jalan Cikuray; dan 8) Jalan Ciledug.

Adapun jumlah PKL Garut Kota yang tercatat di Dinas Perindustrian, Perdagangan, dan Pasar (Disperindagpas) Kabupaten Garut tahun 2015 sebanyak 1.318 pedagang. Keberadaan PKL Garut Kota seakan menjadi dilema bagi Pemerintah Daerah (Pemda) Garut. Maraknya PKL yang memadati jantung kota, di satu sisi memberi dampak positif berupa tergerakannya roda perekonomian masyarakat, baik dalam skala kecil maupun menengah, namun di sisi lain maraknya PKL yang berjualan di pinggir jalan menimbulkan persoalan yang pelik dan menjadi salah satu prioritas penanganan, karena kesemrawutan PKL berimbas pada pudarnya nilai estetik perkotaan, menyempitnya bahu dan badan jalan, serta mencerminkan wilayah 
kumuh perkotaan. Pemda Garut berupaya mencari solusi yang tepat dalam upaya pengayoman, penertiban, dan pembinaan para PKL, salah satunya adalah dengan relokasi PKL ke beberapa lokasi dan gedung yang telah disediakan.

Kesemrawutan Garut Kota yang disebabkan oleh para PKL merupakan persoalan klasik. Ketidaktersediaan tempat bagi para pedagang untuk menjajakan dagangannya merupakan salah satu sebab para PKL berjualan di zona tersebut. Sebagaimana diamanatkan dalam Peraturan Presiden Nomor 125 Tahun 2012 tentang Koordinasi Penataan dan Pemberdayaan Pedagang Kaki Lima, serta Peraturan Menteri Dalam Negeri (Permendagri) Nomor 41 Tahun 2012 tentang Pedoman Penataan dan Pemberdayaan Pedagang Kaki Lima, bahwa peningkatan jumlah pedagang kaki lima di daerah telah berdampak pada terganggunya kelancaran lalu lintas, estetika dan kebersihan serta fungsi prasarana kawasan perkotaan maka diperlukan penataan pedagang kaki lima, maka Pemerintah Kabupaten Garut menuangkannya dalam Peraturan Daerah Kabupaten Garut Nomor 3 Tahun 2014 tentang Rencana Pembangunan Jangka Menengah Daerah (RPJMD) Kabupaten Garut Tahun 2014-2019 dan Peraturan Daerah Kabupaten Garut Nomor 12 Tahun 2015 tentang Ketertiban, Kebersihan, dan Keindahan. Konkretnya, melalui Kepbup Garut Nomor 511.23/Kep. 790-Admrek/2014, upaya penataan pun ditempuh oleh Pemda Garut sebagai langkah membenahi pusat kota, sehingga dapat memberikan kenyamanan baik bagi pribumi maupun para wisatawan.

Adapun dalam pelaksanaannya, diberlakukan Pemantauan (Monitoring) Kebijakan yang dilaksanakan oleh Bupati/ Walikota dan sekurang-kurangnya dilakukan dua kali dalam setahun sebagaimana termaktub dalam Pasal 45 ayat 1 dan 2 Permendagri No. 41 Tahun 2012. Pemantauan Kebijakan tersebut kemudian dijawatahkan kepada Tim Penataan dan Pemberdayaan Pedagang Kaki Lima Kabupaten Garut. Pemantauan diperlukan agar kesalahan awal dapat segera diketahui dan dapat dilakukan tindakan perbaikan, menjaga agar kebijakan yang sedang diimplementasikan sesuai dengan tujuan dan sasaran, menemukan kesalahan sedini mungkin sehingga mengurangi risiko yang lebih besar, serta melakukan tindakan modifikasi terhadap kebijakan apabila hasil Pemantauan mengharuskan untuk itu. Pemantauan memiliki andil yang besar dalam keberlangsungan suatu kebijakan, sehingga dalam pelaksanaannya diharapkan dapat sesuai dengan koridor tujuan dan sasaran yang ingin dicapai.

Bukan perkara mudah bagi Pemda Garut untuk menertibkan PKL Garut Kota, membutuhkan suatu pendekatan yang holistis, komprehensif, serta berwawasan ekologis, sehingga dapat menciptakan suatu kebijakan yang menguntungkan bagi semua pihak. Berdasarkan fenomena-fenomena yang Penulis temukan di lapangan, Penulis merumuskan indikasi masalah ke dalam beberapa poin sebagai berikut: 1) Tim Penataan dan Pemberdayaan Pedagang Kaki Lima Kabupaten Garut belum memiliki pedoman baku mengenai petunjuk pelaksanaan (Juklak) dan petunjuk teknis (Juknis) terkait dengan Pemantauan Kebijakan Penataan Pedagang Kaki Lima di Kecamatan Garut Kota; 2) Perlakuan Pemda Garut yang kurang memenuhi asas keadilan maupun kesamaan dalam merelokasi para PKL, cenderung tidak adil dalam membuat keputusan, dan inkonsisten terhadap pelaksanaan kebijakan yang telah dibuatnya sendiri. Banyaknya PKL yang direlokasi tidak diimbangi dengan ketersediaan gedung. Hal ini berdampak pada masih adanya sebagian PKL yang dipindahkan ke zona kuning yang notabene lebih dekat ke pusat perbelanjaan maupun trotoar sebagai 
akses pejalan kaki, sehingga para PKL yang telah menempati gedung pun merasa perlakuan Pemda Garut kurang memenuhi asas keadilan dan kesamaan. Permasalahan ini kemudian memicu timbulnya ekses lain, yaitu para PKL yang telah menempati gedung kemudian kembali berjualan di tempat semula; 3) Kurangnya promosi yang digalakkan oleh Pemda Garut mengakibatkan para PKL yang telah menempati kavling gedung menjadi enggan menempatinya dan lebih memilih untuk kembali berdagang di tempat semula. Gedung PKL pun menjadi sepi dari para pedagang, sehingga minat konsumen menurun secara drastis untuk berbelanja di gedung tersebut. Bagi para PKL yang masih tetap bertahan, posisi semacam ini malah tidak menguntungkan, melainkan mencekik mata pencaharian para PKL. Gedung pun menjadi terbengkalai dan hanya sesekali dibuka; dan 4) Upaya relokasi tidak dibarengi dengan sarana dan prasarana yang memadai bagi para PKL. Lokasi gedung kurang strategis, Gedung PKL 1 dan 2 berjarak $\pm 1 \mathrm{~km}$ pusat perbelanjaan (Pengkolan Garut), sehingga apabila berjalan kaki mesti ditempuh cukup jauh dengan karakter relief menanjak, hal ini mengurangi minat masyarakat yang ingin berbelanja untuk mengakses lokasi gedung tersebut. Adanya keinginan yang kuat dari Pemda Garut untuk membenahi para PKL yang berjualan di pusat keramaian kota tidak diimbangi dengan ketersediaan gedung yang mencukupi, dari sekitar 876 pedagang yang direlokasi, hanya 467 di antaranya yang mendapatkan kavling di gedung PKL 1 dan 2. Hal tersebut mengindikasikan bahwa sisanya ditempatkan di tempat relokasi sementara yang notabene secara kondisi tidak berbeda jauh dengan tempat semula mereka berjualan. Hal ini tentu dapat memantik kecemburuan sosial antar pedagang, yang mana masih terdapat sebagian pedagang yang direlokasi ke tempat lain dalam kondisi semula dengan tenda dan gerobak, ataupun emperan di pinggir jalan, tidak seperti para pedagang yang mendapat jatah relokasi di Gedung PKL 1 dan 2 yang memiliki fasilitas lapak dagangan, air bersih, dan listrik tanpa dipungut biaya apapun, walaupun ada sebagian pedagang yang membangun lapaknya dengan biaya sendiri. Ditambah lagi dengan tempat relokasi sementara di beberapa titik (Zona Kuning) seperti Jalan Pasar Baru dari Perempatan Gunung Payung s/d Perempatan Guntur, Perempatan A. Yani Mandalagiri s/d Perempatan Guntur, dan Depan Halaman Islamic Center eks. Kantor Perdagangan di Jalan Pramuka, yang belum tentu strategis bagi para pedagang.

\section{METODE PENELITIAN}

\begin{tabular}{llr}
\multicolumn{1}{c}{ Guna memahami } & mengapa \\
Pemantauan & Kebijakan & Penataan \\
Pedagang Kaki Lima di Kecamatan Garut \\
Kota oleh Tim Penataan dan \\
Pemberdayaan
\end{tabular}
Kabupaten Garut tidak berdampak kuratif, maka Penulis menggunakan metode penelitian kualitatif sebagai metodenya. Penulis menganggap bahwa metode penelitian kualitatif relevan sebagai dasar metode dalam penelitian ini, karena fenomena yang terjadi tidak memungkinkan diukur secara tepat (dikuantifikasi), sehingga guna mendapatkan pemahaman yang tepat diperlukan eksplorasi kepada para partisipan. Melalui metode penelitian kualitatif ini, Penulis dapat mengkaji perspektif partisipan yang memiliki otoritas, data, informasi, maupun keterkaitan mengenai Pemantauan Kebijakan Penataan Pedagang Kaki Lima di Kecamatan Garut Kota oleh Tim Penataan dan Pemberdayaan Pedagang Kaki Lima Kabupaten Garut. Perspektif partisipan dikaji dengan tujuan untuk memahami fenomena-fenomena sosial dari perspektif partisipan terkait. Adapun dalam mengembangkan dan menggambarkan penelitian, Penulis menggunakan pendekatan penelitian deskriptif. 
Penelitian dengan pendekatan deskriptif ini dilakukan guna mengetahui nilai variabel mandiri dengan memerhatikan kejadian-kejadian atau peristiwa-peristiwa berdasarkan data atau fakta yang sedang berlangsung, yang kemudian disusun dan dianalisis sehingga dapat ditarik kesimpulan yang dapat menggambarkan suatu masalah yang sedang terjadi. Pendekatan penelitian deskriptif pun meliputi penjelasan mengenai data yang dikumpulkan, sehingga dapat menjelaskan kompleksitas suatu permasalahan. Data diperoleh dengan menggunakan studi kepustakaan dan studi lapangan berupa observasi nonpartisipan, wawancara mendalam, dan dokumentasi. Teknik triangulasi sumber dijadikan sebagai pemeriksaan keabsahan data dalam penelitian ini, kemudian datadata tersebut direduksi, disajikan, dan ditarik simpulan.

\section{HASIL DAN PEMBAHASAN}

Hasil penelitian yang Penulis lakukan menunjukkan bahwa: 1) Pemantauan (Monitoring) memang rutin dilakukan oleh Tim Penataan dan Pemberdayaan Pedagang Kaki Lima, akan tetapi dalam pelaksanaannya tidak mengacu pada petunjuk pelaksanaan (Juklak) dan petunjuk teknis (Juknis), dengan alasan tidak terdapat Juklak dan Juknis yang mengatur tentang pelaksanaan Pemantauan; 2) Tim Penataan dan Pemberdayaan Pedagang Kaki Lima tidak mendasarkan monitoring pada indikatorindikator tertentu, sehingga dalam pelaksanaannya hanya mendasarkan pada apa yang ditemukan di lapangan; dan 3) Walaupun tidak ada Juklak dan Juknis mengenai Pemantauan, bukan berarti tidak ada dokumen yang terkait dengan Pemantauan. Dokumen tersebut berupa Nota Dinas yang isinya merupakan hasil Pemantauan di lapangan, kemudian isi dari Nota Dinas tersebut disampaikan pada briefing-briefing Tim Penataan dan Pemberdayaan Pedagang Kaki Lima.
Adapun beberapa kegiatan yang dilakukan oleh Tim Penataan dan Pemberdayaan Pedagang Kaki Lima dalam lingkup Pemantauan Kebijakan ini, antara lain: 1) Monitoring pelaksanaan kebijakan oleh pihak-pihak terkait untuk mengukur seberapa tercapai kebijakan ini dalam pelaksanaannya; 2) Membuka ruang dialog serta sosialisasi lanjutan kepada para Pedagang Kaki Lima; 3) Memberikan bantuan berupa gerobak dagang gratis kepada para Pedagang Kaki Lima yang bersedia berjualan di Jalan Pasar Baru (zona kuning); 4) Melakukan promosi-promosi berupa penyebaran kupon diskon bagi para konsumen, pameran-pameran, serta perayaan hari istimewa; dan 5) Melakukan penindakan/ penertiban bagi pelanggar, dalam bentuk razia secara berkala dan operasi yustisi (sidang di tempat).

\section{SIMPULAN DAN SARAN}

Berdasarkan hasil penelitian yang telah Penulis paparkan pada bab sebelumnya, dapat disimpulkan bahwa Pemantauan Kebijakan Penataan Pedagang Kaki Lima di Kecamatan Garut Kota oleh Tim Penataan dan Pemberdayaan Pedagang Kaki Lima Kabupaten Garut tidak efektif, karena Pemantauan Kebijakan hanya dimaknai secara harfiah, dalam menghasilkan informasi pun tidak melakukan elaborasi yang mendalam, seperti pada aspek Kepatuhan, Pemeriksaan, Akuntansi, dan/ atau Eksplanasi.

Dampak dari Pemantauan Kebijakan yang hanya dimaknai secara harfiah adalah pada pelaksanaannya belum memiliki pedoman yang baku, sehingga tidak dapat diidentifikasi penyebab dari permasalahan-permasalahan yang terjadi di lapangan, informasi yang dihasilkan dari proses Pemantauan Kebijakan pun cenderung menjadi terbatas dan dangkal. Hal ini berimplikasi terhadap langkah lanjutan yang semestinya ditempuh oleh Tim Penataan dan Pemberdayaan Pedagang Kaki Lima, upaya koreksi 
pelaksanaan kebijakan menjadi tidak tepat guna dan hasil guna dikarenakan informasi yang dihasilkan dari Pemantauan Kebijakan tidak begitu menyokong, hal inilah yang membuat Kebijakan Penataan Pedagang Kaki Lima belum dapat dilaksanakan dengan baik sesuai koridor tujuannya.

Tim Penataan dan Pemberdayaan Pedagang Kaki Lima memang telah melakukan upaya Pemantauan Kebijakan, sebagaimana yang telah diamanatkan dalam Pasal 45 ayat 1 dan 2 Permendagri No. 41 Tahun 2012. Akan tetapi, dalam pelaksanaannya belum memiliki pedoman yang baku, sehingga informasi yang dihasilkan pun hanya mengandalkan dari apa yang terlihat di lapangan, bukan dengan penelitian yang mengkaji lebih dalam dari berbagai sudut pandang, seperti dari Aspek Kepatuhan, Pemeriksaan, Akuntansi, dan Eksplanasi. Berdasarkan hasil penelitian Penulis, walaupun Tim Penataan dan Pemberdayaan Pedagang Kaki Lima dalam Pemantauannya tidak berpedoman atau tidak mengelompokkan hasil Pemantauannya ke dalam berbagai aspek tersebut, tetapi sedikitnya data yang Penulis peroleh dapat dikelompokkan ke dalam Aspek Kepatuhan dan Pemeriksaan, adapun untuk aspek lainnya Penulis tidak memperoleh data pendukung yang dapat diklasifikasikan ke dalam aspek Akuntansi maupun Eksplanasi dikarenakan Tim Penataan dan Pemberdayaan Pedagang Kaki Lima tidak melakukan analisis sejauh itu berdasarkan dokumen-dokumen yang diperoleh maupun dari hasil wawancara.

Adapun saran yang Penulis rekomendasikan agar ke depannya hasil dari pelaksanaan Pemantauan Kebijakan oleh Tim Penataan dan Pemberdayaan Pedagang Kaki Lima dapat lebih efektif yaitu dengan merumuskan Petunjuk Pelaksanaan (Juklak) dan Petunjuk Teknis (Juknis) sebagai pedoman dalam melakukan Pemantauan Kebijakan. Penulis menyarankan dalam penyusunan
Juklak dan Juknis ini melibatkan pula unsur akademisi maupun Badan Pusat Statistik, sehingga dalam pembahasannya dapat lebih komprehensif karena terdiri dari berbagai macam sudut pandang, dengan harapan dapat tercipta Juklak dan Juknis yang handal, tepat guna, dan hasil guna. Adapun substansi yang mesti tercantum dalam Juklak dan Juknis ini ialah sebagai berikut.

1. Diperlukan kejelasan timeline pelaksanaan Pemantauan Kebijakan, sehingga hasil Pemantauan Kebijakan dari waktu ke waktu dapat terpantau dengan baik perbedaannya;

2. Pelaksanaan Pemantauan Kebijakan ini bukan saja oleh Tim Penataan dan Pemberdayaan Pedagang Kaki Lima, melainkan diperlukan keterlibatan dari para Akademisi maupun Badan Pusat Statistik, sehingga hasilnya pun dapat lebih akurat dan mendalam;

3. Diperlukan kejelasan aspek yang berfungsi sebagai pedoman/ acuan dalam melakukan Pemantauan Kebijakan, seperti aspek Kepatuhan, Pemeriksaan, Akuntansi, dan Eksplanasi;

4. Diperlukan kejelasan dalam pendekatan Pemantauan Kebijakan, baik itu menggunakan Akuntansi Sistem Sosial, Eksperimentasi Sosial, Pemeriksaan Sosial, ataupun Sintesis riset-praktik. Pendekatan-pendekatan ini berguna sebagai cara untuk memantau keluaran dan dampak kebijakan. Pendekatan yang dirasa paling koheren dengan kondisi di lapangan kemudian kemudian dipilih, diperdalam skema pelaksanaannya, dan disesuaikan teknik pemantauannya, sehingga didapatkan pola yang baku dalam pelaksanaan Pemantauan Kebijakan ini;

5. Hasil dari Pemantauan Kebijakan ini bukan dibuat Nota Dinas semata, melainkan berupa Dokumen Hasil Pemantauan Kebijakan, sehingga dapat lebih terstruktur, terukur, dan teratur, hasilnya pun lebih memadai 
sebagai bahan koreksi kebijakan dan dapat dijadikan sebagai referensi di kemudian hari apabila dibutuhkan; dan

6. Dokumen Pemantauan Kebijakan bukan hanya dijadikan sebagai bahan briefing di internal Tim Penataan dan Pemberdayaan Pedagang Kaki Lima saja, melainkan juga didiskusikan dengan akademisi, sehingga temuantemuan tersebut dapat dicarikan jalan keluar (solusi) yang lebih komprehensif dan efektif.

\section{UCAPAN TERIMA KASIH}

Penulis menyadari bahwa tanpa bantuan serta bimbingan dari berbagai pihak, mulai dari awal hingga akhir penyusunan Skripsi ini, akan dirasa sangat sulit bagi Penulis untuk menyelesaikannya. Oleh karena itu, Penulis memberikan penghormatan yang setinggi-tingginya dan ucapan terima kasih yang sebesar-besarnya kepada pihak-pihak yang telah berkenan membantu Penulis dalam menyelesaikan penyusunan Skripsi ini.

\section{DAFTAR PUSTAKA}

Buku

Agus, S. 2006. Teori dan Paradigma

Penelitian Sosial. Yogyakarta: Tiara.

Bungin, B. 2011. Metodologi Penelitian

Kuantitatif. Jakarta: Kencana.

Dror, Y. 1971. Ventures in Policy

Science. New York, USA: Elsevier.

Dunn, W. N. 1999. Pengantar Analisis

Kebijakan Publik (Terj.).

Yogyakarta: Gadjah Mada

University Press.

Faisal, S. 1990. Penelitian Kualitatif:

Dasar-dasar dan Aplikasi. Malang:

Yayasan Asah Asih Asuh (YA3)

Malang.

Kent, G. 1971. Policy Analysis for Action Recommendations. USA: ARPA.
Moelong, L. J. 2007. Metode Penelitian Kualitatif. Bandung: PT. Remaja Rosdakarya.

Nasution, S. 1988. Metode Penelitian Naturalistik Kualitatif. Bandung: Tarsito. Patton, C. V., \& Sawicki, D. S. (1993). Basic Methods of Policy Analysis and

Planning. New Jersey, USA: Prentice Hall.

Raiffa, H. 1968. Decission Analysis.

Spradley, J. 1980. Participant Observation. California: Holt, Rinehart and Winston.

Subarsono, A. 2015. Analisis Kebijakan Publik: Konsep, Teori dan Aplikasi. Yogyakarta: Pustaka Pelajar.

Sugiyono. 2005. Metode Penelitian Kualitatif. Bandung: Alfabeta.

Sugiyono. 2012. Metode Penelitian Kuantitatif, Kualitatif, dan $R \& D$. Bandung: Alfabeta.

Sugiyono. 2013. Metode Penelitian Administrasi Dilepngkapi dengan Metode R\&D. Bandung: Alfabeta.

Wahab, S. A. 2012. Analisis Kebijakan: dari Formulasi ke Penyusunan Model-model Implementasi Kebijakan Publik. Jakarta: PT Bumi Aksara.

Widodo, J. 2013. Analisis Kebijakan Publik: Konsep dan Aplikasi Analisis Proses Kebijakan Publik. Malang: Bayu Media Publishing.

Wiersma, W. 1986. Research Methods in Education, an Introduction (Vol. 4th Edition). Boston: Allyn and Bacon. 
Peraturan Perundang-undangan

Undang-undang Dasar Republik Indonesia Tahun 1945.

Undang-undang Nomor 39 Tahun 1999 tentang Hak Azasi Manusia.

Undang-undang Nomor 22 Tahun 2009 tentang Lalu Lintas dan Angkutan Jalan.

Peraturan Pemerintah Nomor 34 Tahun 2006 tentang Jalan.

Peraturan Presiden Nomor 125 Tahun 2012 tentang Koordinasi Penataan dan Pemberdayaan Pedagang Kaki Lima.

Peraturan Menteri Dalam Negeri Nomor 41 Tahun 2012 tentang Pedoman Penataan dan Pemberdayaan Pedagang Kaki Lima.

Peraturan Daerah Kabupaten Garut Nomor 3 Tahun 2014 tentang Rencana Pembangunan Jangka Menengah Daerah Kabupaten Garut Tahun 2014-2019.

Peraturan Daerah Kabupaten Garut Nomor 12 Tahun 2015 tentang Ketertiban, Kebersihan, dan Keindahan.

Keputusan Bupati Garut Nomor 511.23/Kep. 790-Admrek/2014 tentang Tim Penataan dan Pemberdayaan Pedagang Kaki Lima di Kabupaten Garut.

Keputusan Bupati Garut Nomor 511.3/Kep. 201-Satpol PP/2015 tentang Pembentukan Tim Pengamanan Penertiban Pedagang Kaki Lima di Wilayah Kabupaten Garut.

Surat Himbauan Nomor 300/ 173-Satpol PP/ 2016.

\section{Jurnal}

Ericson, R. F. 1970. The Policy Analysis Role of the Contemporary University.Policy Sciences, I(4).

Mayer, I. S., Daalen, C. E., dan Bots, P. W. 2004. Perspectives on policy analyses: a framework for understanding and design. International Journal Technology Policy and Management.

Mualim, K. 2008. Analisis Kebijakan Penataan Pedagang Kaki Lima (PKL) di Simpang Lima Kabupaten Pati. Jurnal Ilmu Administrasi dan Kebijakan Publik (JIAKP) Universitas Diponegoro, $V(1)$.

Rahmawati, V. K., dan Patta, J. 2015. Penataan PKL di Kota Surakarta: Mengapa Bisa Berhasil ? Jurnal Perencanan Wilayah dan Kota A SAPPK Institut Teknologi Bandung, $\operatorname{IV}(2)$.

\section{Media Online}

FOKUSJabar.Com. (2016, September 15). Ratusan Massa MPKLG Kembali Datangi Gedung DPRD Garut. Diambil kembali dari fokusjabar.com: http://fokusjabar.com/2016/09/15/rat usan-massa-mpklg-kembali-datangigedung-dprd-garut/

GarutExpress1. (2016, September 19). Akhirnya Bupati "Ngéléhan," PKL Diizinkan Kembali Berdagang di Kawasan Pengkolan. Diambil kembali dari Garut Express: http://garut-express.com/akhirnyabupati-ngelehan-pkl-diizinkankembali-berdagang-di-kawasanpengkolan/

GarutExpress1. (2016, Agustus 04). Gedung PKL Intan Medina di Garut, Jadi Sarang Tempat Maksiat. 
Diambil kembali dari Garut Express: http://garut-express.com/gedung-pklintan-medina-garut-jadi-sarangtempat-maksiat/

Pemda Garut. (2015, Desember 21). Pemkot Tegal Belajar Penataan PKL di Garut. Diambil kembali dari garutkab.go.id:

http://garutkab.go.id/pub/news/detail /12095-pemkot-tegal-belajarpenataan-pkl-di-garut.html

Poros Garut. (2016, Agustus 20). Gedung PKL Garut Jadi Mubazir dan Nyaris Kumuh. Diambil kembali dari PorosGarut.com: https://www.porosgarut.com/gedung -pkl-garut-jadi-mubazir-dan-nyariskumuh/

\section{Sumber Dokumentasi Lainnya}

Dinas Perindustrian, Perdagangan, dan Pasar (Disperindagpas) Kabupaten Garut.

Kantor Kecamatan Garut Kota.

Koninklijk Instituut voor Taal-, Land-en Volkenkunde (KITLV) Digital Image Library. 